\title{
Doubts and Concerns about Isolated Maternal Hypothyroxinemia
}

\author{
Mariacarla Moleti, Francesco Trimarchi, and Francesco Vermiglio \\ Sezione di Endocrinologia, Dipartimento Clinico Sperimentale di Medicina e Farmacologia, Università de Messina, \\ 98125 Messina, Italy \\ Correspondence should be addressed to Francesco Vermiglio, francesco.vermiglio@unime.it
}

Received 23 February 2011; Accepted 10 April 2011

Academic Editor: Kris Gustave Poppe

Copyright ( $\odot 2011$ Mariacarla Moleti et al. This is an open access article distributed under the Creative Commons Attribution License, which permits unrestricted use, distribution, and reproduction in any medium, provided the original work is properly cited.

There is evidence that isolated maternal hypothyroxinemia may have detrimental effects on both mother and foetus. Nonetheless, this condition is still far from being universally accepted as a separate thyroid disease, and a standard definition of this state of mild thyroid underfunction is still lacking. We will review the biochemical criteria used to define isolated maternal hypothyroxinemia, together with current methodological issues related to FT4 assays. We will also discuss its epidemiological impact in both iodinedeficient and-sufficient areas, and the effectiveness of iodine prophylaxis on maternal thyroid function and neuropsychomotor development in offspring.

\section{Introduction}

The literature of the last few decades provides evidence that any decrease in thyroid hormone levels during pregnancy may be harmful for both mother and foetus [1]. The vast majority of pertinent studies refer to welldefined clinical presentations of maternal thyroid underfunction, namely, overt hypothyroidism $(\mathrm{OH})$ and subclinical hypothyroidism $(\mathrm{SH})$, both these conditions being characterized by supra-normal serum TSH levels, with $(\mathrm{OH})$ or without (SH) abnormally low FT4 concentrations. Besides these forms, a milder presentation of maternal thyroid underactivity, described as isolated maternal hypothyroxinemia, has been reported. This condition, characterized by low serum FT4 concentrations but normal serum TSH concentrations, is now recognized as possibly responsible for adverse maternal and foetal/neonatal outcomes $[2,3]$.

This paper aims to discuss some specific issues related to isolated hypothyroxinemia, including its epidemiological impact. In addition, the need to identify and treat early hypothyroxinemia will be briefly discussed.

\section{Isolated Maternal Hypothyroxinemia: Which Is the Correct Definition?}

Although almost 40 years have elapsed since Evelyn Man [4] first introduced the concept of hypothyroxinemia being associated with pregnancy, a precise definition of this condition is still lacking.

Analysis of published studies dealing with isolated hypothyroxinemia reveals that the biochemical criteria on the basis of which maternal hypothyroxinemia is currently diagnosed are quite variable (Table 1). In the studies carried out in the Netherlands by Pop and coworkers, maternal hypothyroxinemia was defined by FT4 levels below the 10th percentile and concomitant TSH values $<2.0 \mathrm{mU} /$ liter [57]. Similarly, Berbel et al. [8] classified as hypothyroxinemic those women who were found to have FT4 values below the 10th percentile. However, TSH concentrations were considered to be normal up to $4.8 \mathrm{mUI} / \mathrm{liter}$, that is to say at values more than twice higher than that adopted in the Dutch studies. In a recent population-based cohort study in the Netherlands [9], women with TSH values $<2.5 \mathrm{mU} /$ liter were diagnosed as affected by mild and severe hypothyroxinemia 
TABLE 1: Biochemical criteria used to define isolated maternal hypothyroxinemia and its epidemiological impact.

\begin{tabular}{|c|c|c|c|c|c|c|}
\hline $\begin{array}{l}\text { Author } \\
\text { (reference number) } \\
\text { (year) country }\end{array}$ & $\begin{array}{l}\text { Lower FT4 } \\
\text { percentile } \\
\text { (pmol/liter) } \\
\end{array}$ & $\begin{array}{l}\text { Manufacturer's } \\
\text { FT4 reference } \\
\text { range (pmol/liter) }\end{array}$ & $\begin{array}{l}\text { Upper TSH limit } \\
\text { (mU/liter) }\end{array}$ & $\begin{array}{l}\text { Manufacturer's } \\
\text { TSH reference } \\
\text { range (mU/liter) }\end{array}$ & $\begin{array}{c}\text { Prevalence of isolated } \\
\text { hypo-thyroxinemia } \\
(\%)\end{array}$ & $\begin{array}{c}\text { Gestational age of } \\
\text { hypo-thyroxinemia } \\
\text { assessment } \\
\end{array}$ \\
\hline $\begin{array}{l}\text { Pop et al. [5] (1999) } \\
\text { The Netherlands }\end{array}$ & $\begin{array}{c}10 \text { th } \\
\text { (1st tr. 10.4) }\end{array}$ & $8.8-18.0^{\mathrm{a}}$ & 2.0 & $0.15-2.0$ & NR & \\
\hline $\begin{array}{l}\text { Pop et al. [6] (2003) } \\
\text { The Netherlands }\end{array}$ & $\begin{array}{c}\text { 10th } \\
\text { (1st tr. 12.4) }\end{array}$ & $8.7-19.6^{\mathrm{a}}$ & 2.0 & $0.15-2.0$ & NR & \\
\hline $\begin{array}{l}\text { Kooistra } \\
\text { et al. [7] (2006) } \\
\text { The Netherlands }\end{array}$ & $\begin{array}{l}10 \text { th } \\
\text { (NR) }\end{array}$ & $8.7-19.6^{\mathrm{a}}$ & 2.0 & $0.15-2.0$ & NR & \\
\hline $\begin{array}{l}\text { Casey } \\
\text { et al. [10] (2007) } \\
\text { USA }\end{array}$ & $\begin{array}{c}2.5 \text { th } \\
(\text { GW 6-20 11.1) }\end{array}$ & $11.2-24.7^{\mathrm{b}}$ & 3.0 & NR & $1.3 \%$ & 1st half of gestation \\
\hline $\begin{array}{l}\text { Vaidya } \\
\text { et al. [11] (2007) } \\
\text { UK }\end{array}$ & $\begin{array}{c}2.5 \text { th } \\
\text { (1st tr. 10.6) }\end{array}$ & $12.0-23.0^{c}$ & 3.0 & $0.27-4.2$ & $1.6 \%\left(7.8 \% \%^{*}\right)$ & 1st trimester \\
\hline $\begin{array}{l}\text { Cleary-Goldman } \\
\text { et al. [13] (2008) } \\
\text { USA }\end{array}$ & $\begin{array}{c}\text { 2.5th } \\
\text { (1st tr. } 9.3 ; \\
\text { 2nd tr. } 9.3 \text { ) }\end{array}$ & $10.3-24.4^{\mathrm{b}}$ & $\begin{array}{l}\text { 1st trim } 4.28 .2 \mathrm{nd} \\
\text { trim. } 3.93\end{array}$ & NR & $\begin{array}{l}2.1 \% \\
2.3 \%\end{array}$ & $\begin{array}{l}\text { 1st trimester } 2 \mathrm{nd} \\
\text { trimester }\end{array}$ \\
\hline $\begin{array}{l}\text { Moleti } \\
\text { et al. [12] (2009) } \\
\text { Italy }\end{array}$ & $\begin{array}{c}\text { 2.5th } \\
\text { (1st tr. 11.9; } \\
\text { 2nd tr. 10.4; } \\
\text { 3rd tr. 10.3) }\end{array}$ & $11.7-22.0^{\mathrm{d}}$ & $\begin{array}{c}1 \text { st tr. } 2.3 \\
\text { 2nd tr. } 2.8 \\
\text { 3rd tr. } 3.0\end{array}$ & $0.4-4.0$ & $\begin{array}{c}3.2 \% \\
12.7 \% \\
9.5 \%\end{array}$ & $\begin{array}{l}\text { 1st trimester 2nd } \\
\text { trimester 3rd } \\
\text { trimester }\end{array}$ \\
\hline $\begin{array}{l}\text { Berbel } \\
\text { et al. [8] (2009) } \\
\text { Spain } \\
\end{array}$ & 10th (10.5) & $9.1-23.8^{e}$ & 4.8 & $0.38-4.8$ & $\begin{array}{l}23.9 \% \\
20.6 \% \\
26.5 \% \\
\end{array}$ & $\begin{array}{l}\text { 1st trimester } 2 \mathrm{nd} \\
\text { trimester } 3 \mathrm{rd} \\
\text { trimester }\end{array}$ \\
\hline $\begin{array}{l}\text { Shan } \\
\text { et al. [14] (2009) } \\
\text { China }\end{array}$ & 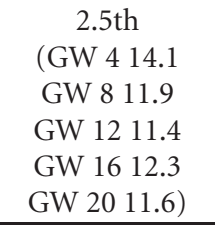 & $10.3-24.5^{\mathrm{b}}$ & $\begin{array}{c}\text { GW } 4 \text { 4 } 4.38 \\
\text { GW } 83.8 \\
\text { GW } 12 \text { 2 } 2.96 \\
\text { GW } 163.29 \\
\text { GW } 203.88\end{array}$ & $0.3-4.8$ & $2.2 \%(0.4 \% *)$ & 1st half of gestation \\
\hline $\begin{array}{l}\text { Henrichs } \\
\text { et al. [9] (2010) } \\
\text { The Netherlands }\end{array}$ & $\begin{array}{c}\text { 10th } \\
(11.76) \\
5 \text { th }(10.96) \\
\end{array}$ & $11.0-25.0^{\mathrm{f}}$ & 2.5 & NR & $\begin{array}{c}8.5 \%(<10 \text { th }) \\
4.3 \%(<5 \text { th })\end{array}$ & GW 13 (median) \\
\hline \multicolumn{7}{|c|}{ 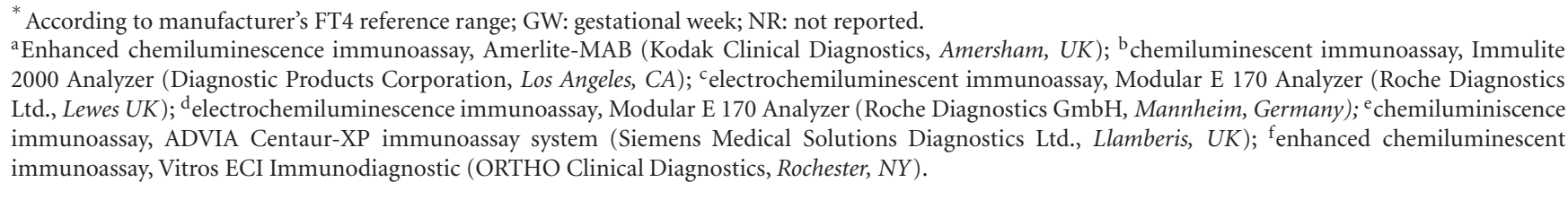 } \\
\hline
\end{tabular}

based on whether their FT4 concentrations were below the 10 th or the 5 th percentile, respectively. In the remaining five studies listed in Table 1, isolated hypothyroxinemia is defined by FT4 values below the 2.5th percentile, but by $\mathrm{TSH}$ values $\leq 3.0 \mathrm{mU} / \mathrm{liter}$ in two of them $[10,11]$, and by values that fall below the upper gestational specific limit in the remaining three [12-14]. In particular, ClearyGoldman and coworkers identified an upper limit for TSH in the 97.5th percentile in a cohort of 10990 women at both 1 st and 2 nd trimester, corresponding to $4.28 \mathrm{mU} /$ liter and $3.93 \mathrm{mU} /$ liter, respectively [13]. Analogously, Shan et al. used TSH gestational age reference intervals, calculated from week 4 up to week 20 of gestation in 120-129 healthy women. The corresponding upper values ranged 2.96-4.38 mU/liter, depending on the week of gestation [14].
Finally, a study from our research group referred to TSH trimester-specific reference ranges derived from 495 healthy women at different stages of pregnancy. The normal upper limits were $2.3 \mathrm{mU} /$ liter, $2.8 \mathrm{mU} /$ liter, and $3.0 \mathrm{mU} /$ liter, at 1st, 2nd, and 3rd trimesters, respectively [12].

From the above, it is clear that the criteria for defining normal levels of FT4 and TSH in pregnant women are far from homogeneous. This variance has obvious diagnostic and therapeutic implications. Indeed, depending on the FT4/TSH threshold considered to be normal, the same biochemical pattern may be variously defined as overt/subclinical hypothyroidism, which requires medical treatment, as isolated hypothyroxinemia, the treatment of which is advocated by some but not by others, or even as normal. 


\section{Are There Normative FT4 and TSH Values to Define Isolated Maternal Hypothyroxinemia?}

Besides the definitions reported in these studies, Morreale De Escobar et al. [2] defined hypothyroxinemia to be any situation characterized by serum FT4 values lower than the 10th percentile value for normal pregnant women with a confirmed adequate iodine intake at comparable weeks of gestation, whether or not there is a concomitant increase in TSH values. Although this definition combines overt hypothyroidism and isolated hypothyroxinemia, it is of great interest as a basis for this discussion in that it emphasizes the need to refer to gestational-specific ranges calculated in properly iodine supplemented women. In the abovementioned studies the reference ranges for FT4 and TSH are in some cases the same as those used for the general population, whereas in others they are specifically calculated using serum pools from normal pregnant women. The latter approach is currently regarded as the most appropriate [15] since pregnancy induces marked changes that invalidate the nonpregnant reference limits as a means of diagnosing thyroid dysfunctions in pregnant women. Indeed, during the 1st trimester, the stimulatory effect of hCG on thyrocytes induces a transient increase in FT4 levels, which is mirrored by a lowering of TSH concentrations. Following this period, serum FT4 concentrations decrease slightly $(10-15 \%$ on average), and serum TSH values steadily return to normal [16]. In line with these variations, both FT4 and TSH reference intervals change throughout pregnancy, depending on gestational age. Thus, the utilization of nonpregnant reference intervals to interpret thyroid function tests in pregnant women carries the risk of misdiagnosis. In a cross-sectional study, Stricker et al. [17] in Switzerland established gestational age-specific reference ranges for free and total T3 and T4, and TSH using more than 1800 blood samples obtained from antibody-negative and iodine sufficient women at different stages of pregnancy. The main finding of this study was that there was a significant difference between the reference intervals of most thyroid parameters in the pregnant population and those reported by the assay manufacturer for nonpregnant subjects. The authors' conclusion was that the interpretation of thyroid function tests in pregnant women using nonpregnant reference intervals could potentially result in the misclassification of a significant percentage of results. It is worth noting that in that study the lower normal limits for FT4 in the pregnant population were higher than those reported by the manufacturer at each interval up to week 30 of gestation, and only began to decrease at late third trimester. Similarly, in a series of healthy, antibody-negative, and iodine sufficient women tested in the first half of pregnancy, Shan et al. [14] found FT4 lower limits to be consistently higher than those of the nonpregnant population. Accordingly, the prevalence of isolated hypothyroxinemia in their cohort of 4800 pregnant women decreased from $2.2 \%$ to less than $0.4 \%$ based on whether the gestational or general population reference ranges were used. Conversely, Vaidya and coworkers [11] found that the prevalence of hypothyroxinemia was $1.6 \%$ according to their own internal FT4 1st trimester-specific reference range, and as high as $7.8 \%$ when they used the manufacturer's general population reference range, the lower FT4 limit in the latter being higher than those found in the pregnant population (12.0 $\mathrm{pmol} /$ liter versus $10.6 \mathrm{pmol} /$ liter). Can the different iodine intake account for these diverging results? Epidemiological data on nutritional iodine status from the regions where the three aforementioned studies were carried out would seem to support this hypothesis. In 2005, Zimmermann et al. [18] reported a median urinary iodine (UI) concentration of $249 \mu \mathrm{g} /$ liter in a sample of 279 pregnant Swiss women, with almost $80 \%$ of them recording UI levels $>140 \mu \mathrm{g} /$ liter. Thus, although nutritional iodine status was not assessed by Stricker et al. [17], the women included in their study were reasonably iodine sufficient, as were those in the Chinese study [14], whose median UI concentration was $180.8 \mu \mathrm{g} /$ liter. Conversely, the available data suggest that pregnant women in the UK, where the population is assumed to be iodine replete, might now be mildly iodine deficient. In particular, a study carried out in the north east of England has shown that 7\% and $40 \%$ pregnant women had UI excretion of less than $50 \mu \mathrm{g} /$ liter and 50-100 $\mu \mathrm{g} /$ liter, respectively [19]. More recent findings seem to confirm comparable data in the south of England, where median UI concentration in a population of pregnant women was $98 \mu \mathrm{g} / \mathrm{liter}$ [20]. Thus, given the possible underlying iodine deficiency in the population examined by Vaidya et al. [11], the resulting reference ranges may not actually reflect normal thyroid function, and the study may consequently have underestimated the prevalence of isolated hypothyroxinemia.

These considerations underline the importance of referring to specific gestational ranges when assessing pregnant women's thyroid function, provided that the women recruited to derive such ranges have an iodine intake that is known to be appropriate to the needs of pregnancy.

Another problem that deserves attention concerns the diagnostic accuracy of FT4 testing. Direct analogue FT4 immunoassays currently used to estimate FT4 concentrations are variously biased by either endogenous or in vitro factors. In particular, these assays are known to be influenced to variable degrees by the physiological changes in thyroxine-binding globulin (TBG) and albumin that occur during pregnancy $[21,22]$. Because of these methodspecific alterations, the same specimens analyzed by different immunoassay platforms may provide remarkably different results [23]. Conversely, methods of analysis based on the physical separation of the free from the protein-bound T4 fraction by equilibrium dialysis (ED) or ultrafiltration (UF), before direct quantification of the hormone content in the dialysate/ultrafiltrate, are generally regarded as reference methods $[24,25]$. However, some theoretical and technical drawbacks seem to exist even with these methods, especially with regard to the separation step [26]. Recently, an International Federation of Clinical Chemistry (IFCC) working group proposed FT4 measurement by ED combined with isotope dilution-liquid chromatography/tandem mass spectrometry (ED ID-LC/tandem MS) as the reference measurement procedure (RMP) to measure serum FT4 [27]. In general, most of current routine immunoassays provide 
lower FT4 values than the RMP, even if divergences seem to be greater for high values rather than for values in the low range $[28,29]$. In a recent study, Anckaert et al. compared the FT4 results by three different immunoassays with those obtained by an ED ID-LC/tandem MS, with the objective of verifying the reliability of these assays for monitoring maternal thyroid function. Interestingly, although all the tested immunoassays were sensitive to alterations in T4binding proteins, two of them gave a FT4 pattern during pregnancy which was similar to that obtained by ED IDLC/tandem MS [30]. In our opinion, the results of this study are very important from a practical point of view, since currently the measurement of FT4 by LC/tandem MS is relatively expensive, technically demanding, and takes too long to be applied for routine clinical practice.

In summary, measurement of FT4 by isotope dilution tandem mass spectrometry provides accurate and reliable results during pregnancy, but these assays are not broadly available. In contrast, automated immunoassays are currently the most widely used systems for measuring FT4, but they are variously biased by several factors, which are responsible for significant method-dependent variations in FT4 measurement in pregnancy. Because of these methodological difficulties, establishing normative values of FT4 for pregnancy is challenging and, whatever the method, it is recommended that method- and gestation-specific reference ranges are used for interpreting results in pregnancy $[15,31]$.

\section{How Common Is Maternal Isolated Hypothyroxinemia?}

Defining the true incidence of isolated maternal hypothyroxinemia is rather difficult, especially, but not only, because of the aforementioned differences in diagnostic criteria used to define the condition. In addition, the epidemiological data presently available are somewhat sparse.

The issue of the epidemiological impact of isolated hypothyroxinemia was very recently reviewed by Krassas et al. [32], who estimated an overall incidence of approximately $2 \%$ in unselected pregnancies. However, it should be noted that wide differences exist among the quoted studies, apparently related mainly to iodine nutrition status in the areas where the studies were conducted. Indeed, in regions where iodine intake is sufficient, as is the case in the United States, the prevalence of isolated hypothyroxinemia ranges between $1.3 \%$ [10] and 2.3\% [13]. It is worth noting that although the US population is generally iodine sufficient, approximately $15 \%$ of women of reproductive age have urinary iodine levels that fall below $50 \mu \mathrm{g} / \mathrm{liter}$, clearly an indication of iodine deficiency [33]. In contrast, in mildly to moderately iodine deficient regions, isolated hypothyroxinemia affects a much higher percentage of women, reaching values up to $25-30 \%[8,12]$. Interestingly, in a very recent study by Henrichs et al. [9] carried out in The Netherlands on a cohort of 3659 women, the prevalence of mild hypothyroxinemia (FT4 < 10th percentile) was $8.5 \%$ and that of severe hypothyroxinemia (FT4 $<5$ th percentile) $4.3 \%$. These figures are significantly higher than those reported in previous studies conducted in iodine sufficient regions $[10,13]$.
The question of when during gestation the diagnosis of maternal hypothyroxinemia is made is an important point that deserves attention when attempting an estimate of the prevalence of this condition. In 2009, we carried out a longitudinal study of 220 consecutive women from a mildly iodine-deficient area with the aim of evaluating the timing of maternal thyroid failure occurrence in conditions of mild iodine deficiency [13]. Although the overall prevalence of maternal isolated hypothyroxinemia over the course of gestation was about $25 \%$, analysis of its frequency distribution revealed that at presentation (<week 12) a comparatively small number of women displayed FT4 values below the 2.5th percentile for gestational age, the vast majority dropping to this limit only later in gestation (12.5\% versus $87.5 \%$ ) (Figure 1). This finding indicates that this state of mild thyroid failure tends to become increasingly frequent as the pregnancy progresses, and our conclusion was that assessing the prevalence of isolated hypothyroxinemia on the basis of a single evaluation during early pregnancy only, has the potential to result in a substantial underestimation of its true prevalence. Notably, in our study only a small proportion (7\%) of women who experienced isolated hypothyroxinemia were found to be antithyroid antibody positive, thus suggesting that features other than autoimmunity might play a major role in the occurrence of this condition. In particular, we speculated that isolated hypothyroxinemia might be the result of a failure of the maternal thyroid to keep up with sustained hormone demand due to a progressive depletion of iodine stores and an inadequate daily iodine supply.

\section{Is Maternal Isolated Hypothyroxinemia an Iodine Deficiency Disorder?}

Although the cause of isolated hypothyroxinemia is not fully understood, an iodine intake that fails to meet the requirements of pregnancy may well be responsible. Indeed, in conditions of mild-moderate iodine deficiency, thyroid stimulation by human chorionic gonadotropin leads to the preferential output of $\mathrm{T} 3$ over $\mathrm{T} 4$, the secretion of the latter becoming inappropriately low relative to the increasing TBG concentrations. This event leads to the progressive desaturation of TBG by T4, ultimately resulting in a decline in FT4 concentrations. Conversely, circulating T3 is normal (or even slightly over the upper limit) and triggers negative feedback on pituitary TSH secretion, the concentrations of which fall within the normal range. As a result, the women are clinically euthyroid even when biochemically hypothyroxinemic $[2,34]$.

The putative pathogenic role of iodine deficiency is now also suggested by clinical studies demonstrating that proper iodine supplementation during pregnancy reduces the risk of developing hypothyroxinemia. This point was addressed by our research group in a longitudinal study aimed at comparing thyroid function in pregnant women who had regularly used iodized salt for at least 2 years prior to becoming pregnant with that of women who began using iodized salt upon becoming pregnant [35]. The main finding 


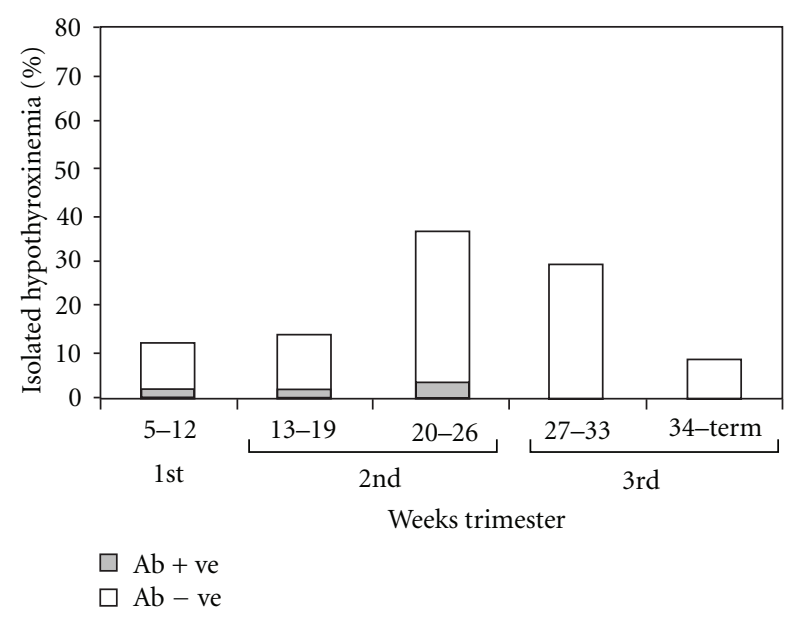

FIGURE 1: Frequency distribution of isolated hypothyroxinemia over the course of gestation in a series of 220 consecutive pregnant women from a mildly iodine-deficient area (from European Journal of Endocrinology, by Bioscientifica [12]).

of this study was that short-term iodine prophylaxis did not protect against the risk of isolated hypothyroxinemia, the prevalence of which was almost 5-fold higher in shortterm than in long-term iodine supplemented women $(36.8 \%$ versus $6.4 \%$ ). Furthermore, in the long-term group isolated hypothyroxinemia could be detected almost exclusively late in gestation, thus suggesting that the greater replenishment of intrathyroidal iodine stores might guarantee an adequate thyroid hormone output for almost the entire period of gestation. In 2009, Berbel et al. [8] reported that iodine supplementation by means of $200 \mu \mathrm{g}$ KI per day was effective in restoring euthyroidism (defined as FT4 concentrations above the 20th percentile) in those women who were found to be hypothyroxinemic at either weeks $4-6$ or $14-16$ of gestation, as well as in maintaining euthyroidism in the remaining women. Finally, we very recently examined the effect of different levels of nutritional iodine intake on maternal thyroid function throughout gestation in a cohort of healthy, antithyroid antibody negative women from a mildly iodine deficient area. The thyroid function of 168 women who had received prenatal preparations containing $150 \mu \mathrm{g}$ of iodine from early pregnancy was compared with that of either 105 women who had regularly used ( $>2 \mathrm{yrs}$ ) iodized salt prior to becoming pregnant or 160 women who had neither taken iodine supplements nor used iodized salt. The regular use of iodine-containing supplements proved effective in reducing, though not in completely eliminating, the risk of inappropriately low FT4 levels during pregnancy, the overall prevalence of isolated hypothyroxinemia in the three study groups being $8.3 \%, 9.5 \%$, and $20 \%$, respectively [36].

Besides the importance of iodine supplementation in preventing/correcting maternal hypothyroxinemia, we would foreground that adequate iodine supply during pregnancy is essential to providing the foetus with enough substrate to draw on for its own thyroid hormone synthesis.
The importance of adequate supply of iodine and thyroid hormone to the developing foetus is emphasized by recent studies of intervention with iodine and L-thyroxine.

In 2009, Velasco et al. [37] compared the cognitive and psychomotor development of 133 infants (aged 3-18 months) born to mothers who had received $300 \mu \mathrm{g}$ of iodine from the first trimester of pregnancy with that of 61 agematched children whose mothers had not received iodine supplements. The most relevant result of this study is that the former had a more favourable psychomotor outcome than those born to mothers who were not treated. Similarly, Berbel et al. [8] showed that the mean developmental quotient in children born to mothers supplemented with a daily dose of $200 \mu \mathrm{g}$ of potassium iodide from 4-6 weeks of gestation was significantly higher than the one recorded for babies born to mothers who had received iodine supplements later in gestation. The authors' conclusion was that a delay of 6-10 weeks in iodine supplementation in hypothyroxinemic mothers at the beginning of gestation increased the risk of neurodevelopmental delay in the progeny.

Finally, a large prospective randomized trial of L-T4 treatment in pregnant women with FT4 levels $<2.5$ th centile and/or TSH >97th centile, the Controlled Antenatal Thyroid Screening Study (CATS), is presently ongoing. The main objectives of this study are to evaluate whether abnormal maternal thyroid function adversely affect neurocognitive function in offspring and to assess the benefits, if any, of maternal L-T4 treatment. Preliminary results from this study suggest that the mean IQ of children born from treated mothers is not different from that of controls. However, when the analysis was restricted to children whose mothers were considered to have been compliant with their L-T4 treatment, a significantly higher proportion of children with IQ $<85$ was found in the untreated group $[31,38]$. Once completed, this study will provide important evidence that should conclusively settle the question of whether or not LT4 treatment of maternal isolated hypothyroxinemia is of benefit in preventing delayed neuropsychological development.

\section{Concluding Remarks}

There is growing evidence of the potential detrimental effects of maternal hypothyroxinemia on both mother and foetus. In particular, maternal hypothyroxinemia was reported to be associated with higher risk of placental abruption, preterm delivery, and increased frequency of Caesarian section [32]. Also, maternal hypothyroxinemia during early gestation may lead to irreversible brain damage in progeny ranging over a broad spectrum of neurological phenotypes, from mental retardation to neurobehavioral impairment, as well as Attention Deficit and Hyperactivity Disorder, among others $[2,5-9,39]$. Nevertheless, this condition is still far from being universally accepted as a separate thyroid disease. This is likely the main reason why a standard definition of this state of mild thyroid underfunction is still lacking. At present, the biochemical criteria used to determine whether or not a woman is affected with isolated hypothyroxinemia are in most cases arbitrarily established. Furthermore, normative 
FT4 gestational ranges appropriately derived from iodine sufficient women are presently lacking [28]. Nor do we currently know the threshold below which the FT4 values should be considered potentially harmful to both gestational outcome and foetal development. Accordingly, there is no consensus on whether the treatment of women with isolated hypothyroxinemia with L-Thyroxine is deemed necessary. In the above mentioned paper by Morreale De Escobar et al., it is suggested that L-Thyroxine treatment should be prescribed in women whose free-T4 concentrations fall below the 10th percentile value, provided that they are also given adequate iodine supplements [2]. The results of currently ongoing studies should provide the evidence needed to conclusively determine whether or not the use of L-T4 in the treatment of isolated hypothyroxinemia is of benefit in preventing foetal brain damage $[31,32,38]$. In the meanwhile, we believe that women found to be hypothyroxinemic should be given substitutive L-thyroxine treatment in order to ensure FT4 levels that are similar to those observed in adequately iodine supplemented women at the same stage of pregnancy [40].

The incidence rates of isolated hypothyroxinemia vary widely among the studies, due to differences in either diagnostic criteria or in the timing of its evaluation, as well as in the iodine nutrition status of the population under examination. Overall, the results of more recent studies seem to indicate that the extent to which isolated hypothyroxinemia may occur is actually higher than previously estimated, and likely much higher than that of both subclinical and overt hypothyroidism. Even more significantly, a nonnegligible prevalence of the condition has been reported in geographical areas where iodine intake, at least for the general population, is assumed to be sufficient. In the absence of any evidence of other causes disrupting maternal thyroid function, the occurrence of isolated hypothyroxinemia in pregnant women from these areas may be interpreted as the result of a purely "gestational" iodine deficiency, that is to say an iodine supply that is inadequate to meet the increased demands of pregnancy.

\section{References}

[1] D. Glinoer and F. Delange, "The potential repercussions of maternal, fetal, and neonatal hypothyroxinemia on the progeny," Thyroid, vol. 10, no. 10, pp. 871-887, 2000.

[2] G. Morreale De Escobar, M. J. Obregon, and F. Escobar Del Rey, "Is neuropsychological development related to maternal hypothyroidism or to maternal hypothyroxinemia?" Journal of Clinical Endocrinology and Metabolism, vol. 85, no. 11, pp. 3975-3987, 2000.

[3] G. M. De Escobar, M. J. Obregón, and F. E. Del Rey, "Role of thyroid hormone during early brain development," European Journal of Endocrinology, Supplement, vol. 151, no. 3, pp. U25U37, 2004.

[4] E. B. Man, "Thyroid function in pregnancy and infancy. Maternal hypothyroxinemia and retardation of progeny," Critical Reviews in Clinical Laboratory Sciences, vol. 3, no. 2, pp. 203-225, 1972.
[5] V. J. Pop, J. L. Kuijpens, A. L. Van Baar et al., "Low maternal free thyroxine concentrations during early pregnancy are associated with impaired psychomotor development in infancy," Clinical Endocrinology, vol. 50, no. 2, pp. 147-155, 1999.

[6] V. J. Pop, E. P. Brouwers, H. L. Vader, T. Vulsma, A. L. Van Baar, and J. J. De Vijlder, "Maternal hypothyroxinaemia during early pregnancy and subsequent child development: a 3-year followup study," Clinical Endocrinology, vol. 59, no. 3, pp. 282-288, 2003.

[7] L. Kooistra, S. Crawford, A. L. Van Baar, E. P. Brouwers, and V. J. Pop, "Neonatal effects of maternal hypothyroxinemia during early pregnancy," Pediatrics, vol. 117, no. 1, pp. 161-167, 2006.

[8] P. Berbel, J. L. Mestre, A. Santamaría et al., "Delayed neurobehavioral development in children born to pregnant women with mild hypothyroxinemia during the first month of gestation: the importance of early iodine supplementation," Thyroid, vol. 19, no. 5, pp. 511-519, 2009.

[9] J. Henrichs, J. J. Bongers-Schokking, J. J. Schenk et al., "Maternal thyroid function during early pregnancy and cognitive functioning in early childhood: the generation $\mathrm{R}$ study," Journal of Clinical Endocrinology and Metabolism, vol. 95, no. 9, pp. 4227-4234, 2010.

[10] B. M. Casey, J. S. Dashe, C. Y. Spong, D. D. McIntire, K. J. Leveno, and G. F. Cunningham, "Perinatal significance of isolated maternal hypothyroxinemia identified in the first half of pregnancy," Obstetrics and Gynecology, vol. 109, no. 5, pp. 1129-1135, 2007.

[11] B. Vaidya, S. Anthony, M. Bilous et al., "Brief report: detection of thyroid dysfunction in early pregnancy: universal screening or targeted high-risk case finding?" Journal of Clinical Endocrinology and Metabolism, vol. 92, no. 1, pp. 203-207, 2007.

[12] M. Moleti, V. Pio Lo Presti, F. Mattina et al., "Gestational thyroid function abnormalities in conditions of mild iodine deficiency: early screening versus continuous monitoring of maternal thyroid status," European Journal of Endocrinology, vol. 160, no. 4, pp. 611-617, 2009.

[13] J. Cleary-Goldman, F. D. Malone, G. Lambert-Messerlian et al., "Maternal thyroid hypofunction and pregnancy outcome," Obstetrics and Gynecology, vol. 112, no. 1, pp. 85-92, 2008.

[14] Z. Y. Shan, Y. Y. Chen, W. P. Teng et al., "A study for maternal thyroid hormone deficiency during the first half of pregnancy in China," European Journal of Clinical Investigation, vol. 39, no. 1, pp. 37-42, 2009.

[15] M. Abalovich, N. Amino, L. A. Barbour et al., "Management of thyroid dysfunction during pregnancy and postpartum: an Endocrine Society Clinical Practice Guideline," The Journal of Clinical Endocrinology and Metabolism, vol. 92, no. 8, pp. S1S47, 2007.

[16] D. Glinoer, "The regulation of thyroid function in pregnancy: pathways of endocrine adaptation from physiology to pathology," Endocrine Reviews, vol. 18, no. 3, pp. 404-433, 1997.

[17] R. Stricker, M. Echenard, R. Eberhart et al., "Evaluation of maternal thyroid function during pregnancy: the importance of using gestational age-specific reference intervals," European Journal of Endocrinology, vol. 157, no. 4, pp. 509-514, 2007.

[18] M. B. Zimmermann, I. Aeberli, T. Torresani, and H. Bürgi, "Increasing the iodine concentration in the Swiss iodized salt program markedly improved iodine status in pregnant women and children: a 5-y prospective national study," American Journal of Clinical Nutrition, vol. 82, no. 2, pp. 388-392, 2005.

[19] M. S. Kibirige, S. Hutchison, C. J. Owen, and H. T. Delves, "Prevalence of maternal dietary iodine insufficiency in the north east of England: implications for the fetus," Archives of 
Disease in Childhood: Fetal and Neonatal Edition, vol. 89, no. 5, pp. F436-F439, 2004.

[20] E. N. Pearce, J. H. Lazarus, P. P. A. Smyth et al., "Perchlorate and thiocyanate exposure and thyroid function in firsttrimester pregnant women," Journal of Clinical Endocrinology and Metabolism, vol. 95, no. 7, pp. 3207-3215, 2010.

[21] K. S. Fritz, R. B. Wilcox, and J. C. Nelson, "Quantifying spurious free T4 results attributable to thyroxine-binding proteins in serum dialysates and ultrafiltrates," Clinical Chemistry, vol. 53, no. 5, pp. 985-988, 2007.

[22] R. H. Lee, C. A. Spencer, J. H. Mestman et al., "Free T4 immunoassays are flawed during pregnancy," American Journal of Obstetrics and Gynecology, vol. 200, no. 3, pp. 260.e1-260.e6, 2009.

[23] M. d'Herbomez, G. Forzy, F. Gasser, C. Massart, A. Beaudonnet, and R. Sapin, "Clinical evaluation of nine free thyroxine assays: persistent problems in particular populations," Clinical Chemistry and Laboratory Medicine, vol. 41, no. 7, pp. 942947, 2003.

[24] N. Kahric-Janicic, S. J. Soldin, O. P. Soldin, T. West, J. Gu, and J. Jonklaas, "Tandem mass spectrometry improves the accuracy of free thyroxine measurements during pregnancy," Thyroid, vol. 17, no. 4, pp. 303-311, 2007.

[25] O. P. Soldin and S. J. Soldin, "Thyroid hormone testing by tandem mass spectrometry," Clinical Biochemistry, vol. 44, no. 1, pp. 89-94, 2011.

[26] S. S. Holm, S. H. Hansen, J. Faber, and P. Staun-Olsen, "Reference methods for the measurement of free thyroid hormones in blood: evaluation of potential reference methods for free thyroxine," Clinical Biochemistry, vol. 37, no. 2, pp. 8593, 2004.

[27] L. M. Thienpont, G. Beastall, N. D. Christofides et al., "Proposal of a candidate international conventional reference measurement procedure for free thyroxine in serum," Clinical Chemistry and Laboratory Medicine, vol. 45, no. 7, pp. 934936, 2007.

[28] J. Gu, O. P. Soldin, and S. J. Soldin, "Simultaneous quantification of free triiodothyronine and free thyroxine by isotope dilution tandem mass spectrometry," Clinical Biochemistry, vol. 40, no. 18, pp. 1386-1391, 2007.

[29] L. M. Thienpont, K. Van Uytfanghe, and S. Van Houcke, "Standardization activities in the field of thyroid function tests: a status report," Clinical Chemistry and Laboratory Medicine, vol. 48, no. 11, pp. 1577-1583, 2010.

[30] E. Anckaert, K. Poppe, K. Van Uytfanghe, J. Schiettecatte, W. Foulon, and L. M. Thienpont, "FT4 immunoassays may display a pattern during pregnancy similar to the equilibrium dialysis ID-LC/tandem MS candidate reference measurement procedure in spite of susceptibility towards binding protein alterations," Clinica Chimica Acta, vol. 411, no. 17-18, pp. 1348-1353, 2010.

[31] R. Negro, O. P. Soldin, M. J. Obregon, and A. Stagnaro-Green, "Hypothyroxinemia and pregnancy," Endocrine Practice, vol. 17, pp. 1-24, 2011.

[32] G. E. Krassas, K. Poppe, and D. Glinoer, "Thyroid function and human reproductive health," Endocrine Reviews, vol. 31, no. 5, pp. 702-755, 2010.

[33] K. L. Caldwell, G. A. Miller, R. Y. Wang, R. B. Jain, and R. L. Jones, "Iodine status of the U.S. population, National Health and Nutrition Examination Survey 2003-2004," Thyroid, vol. 18, no. 11, pp. 1207-1214, 2008.

[34] P. E. Pedraza, M. J. Obregon, H. F. Escobar-Morreale, F. E. Del Rey, and G. M. De Escobar, "Mechanisms of adaptation to iodine deficiency in rats: thyroid status is tissue specific. Its relevance for man," Endocrinology, vol. 147, no. 5, pp. 20982108, 2006.

[35] M. Moleti, V. P. L. Presti, M. C. Campolo et al., "Iodine prophylaxis using iodized salt and risk of maternal thyroid failure in conditions of mild iodine deficiency," Journal of Clinical Endocrinology and Metabolism, vol. 93, no. 7, pp. 2616-2621, 2008.

[36] M. Moleti, B. Di Bella, G. Giorgianni et al., "Maternal thyroid function in different conditions of iodine nutrition in pregnant women exposed to mildly-moderately iodine deficiency: an observational study," Clinical Endocrinology, vol. 74, no. 6, pp. 762-768, 2011.

[37] I. Velasco, M. Carreira, P. Santiago et al., "Effect of iodine prophylaxis during pregnancy on neurocognitive development of children during the first two years of life," Journal of Clinical Endocrinology and Metabolism, vol. 94, no. 9, pp. 3234-3241, 2009.

[38] J. H. Lazarus, “Thyroid function in pregnancy," British Medical Bulletin, vol. 97, no. 1, pp. 137-148, 2011.

[39] F. Vermiglio, V. P. Lo Presti, M. Moleti et al., "Attention deficit and hyperactivity disorders in the offspring of mothers exposed to mild-moderate iodine deficiency: a possible novel iodine deficiency disorder in developed countries," Journal of Clinical Endocrinology and Metabolism, vol. 89, no. 12, pp. 6054-6060, 2004.

[40] M. Moleti, F. Vermiglio, and F. Trimarchi, "Maternal isolated hypothyroxinemia: to treat or not to treat?" Journal of Endocrinological Investigation, vol. 32, no. 9, pp. 780-782, 2009. 


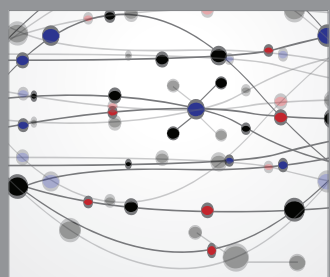

The Scientific World Journal
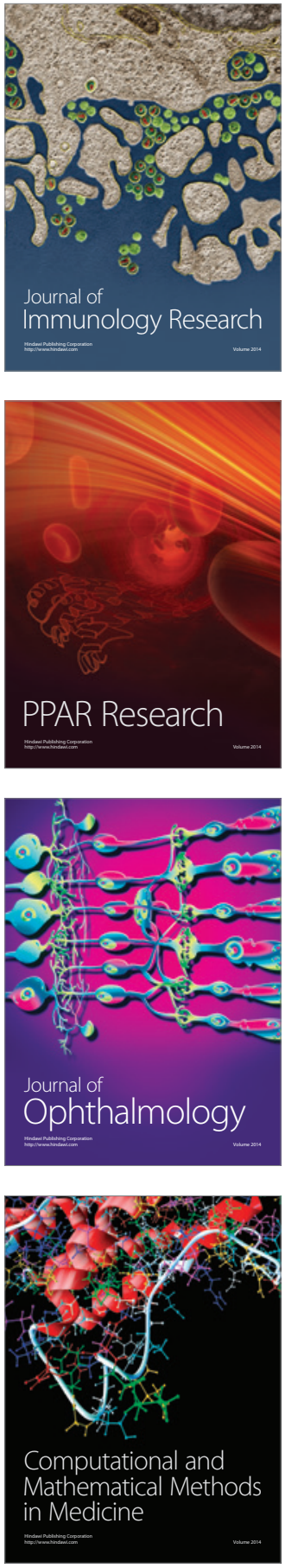

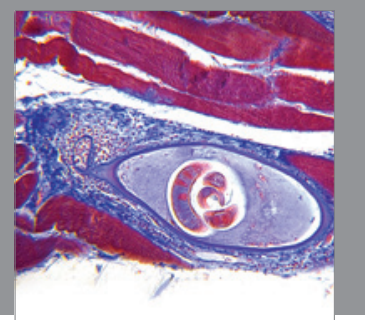

Gastroenterology

Research and Practice
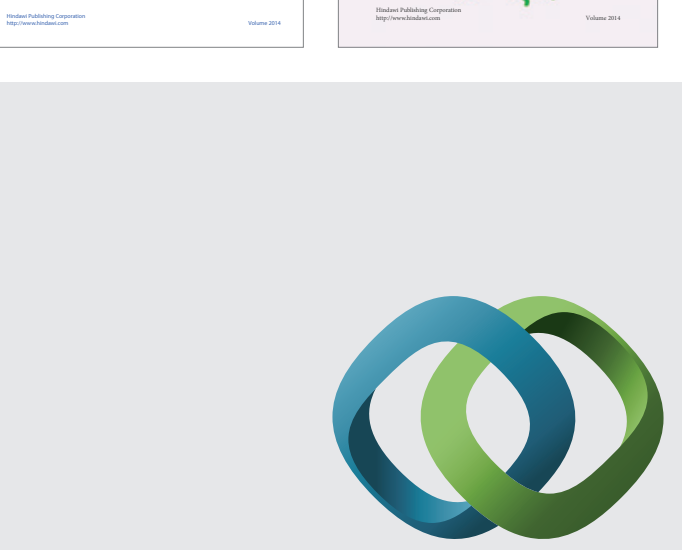

\section{Hindawi}

Submit your manuscripts at

http://www.hindawi.com
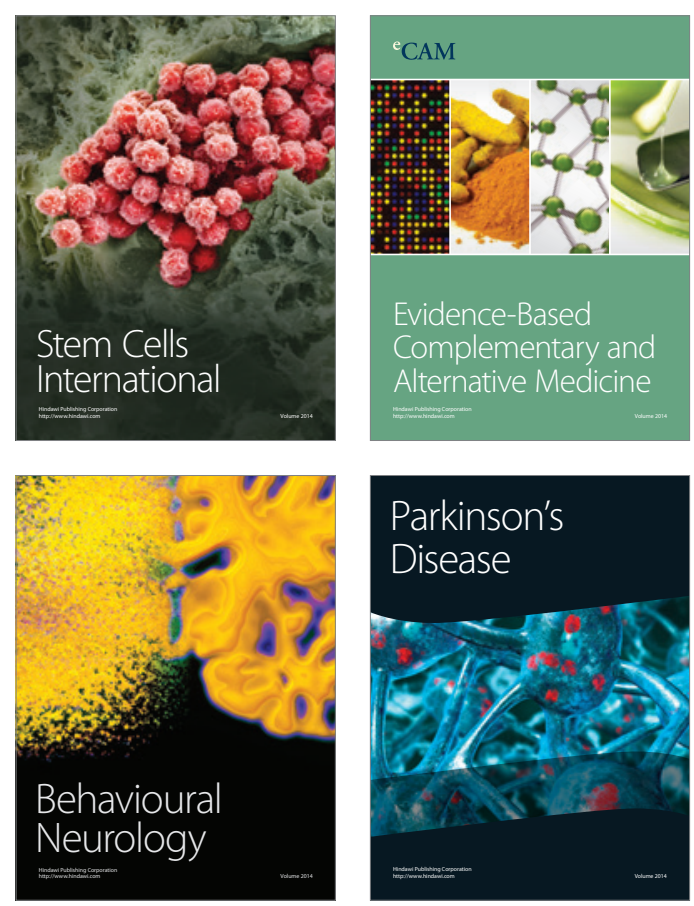

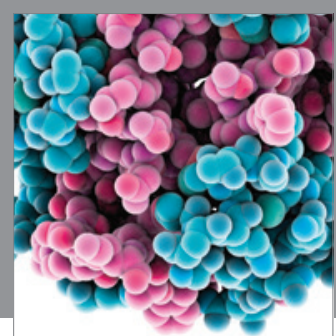

Journal of
Diabetes Research

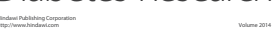

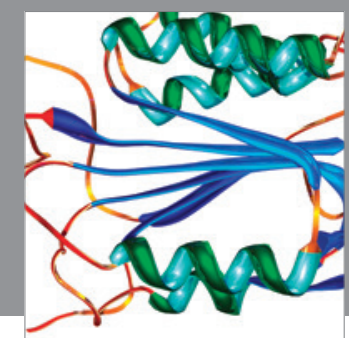

Disease Markers
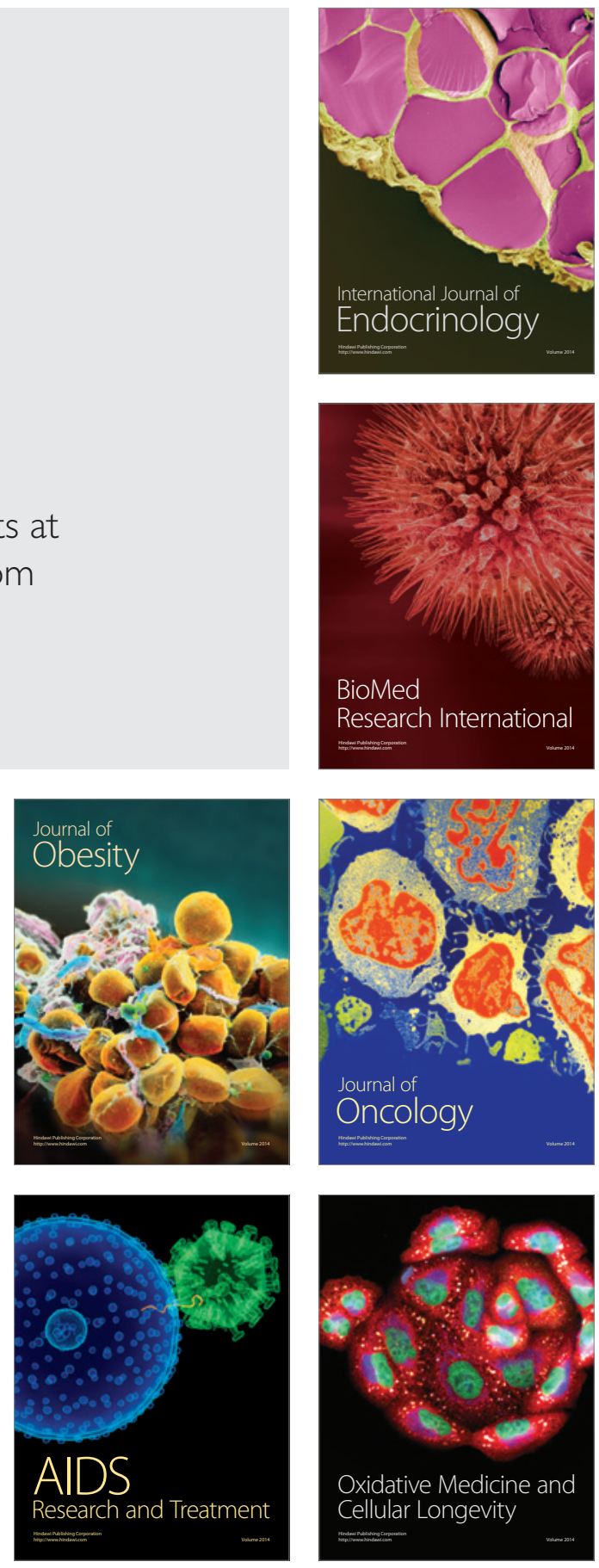